\title{
Editorial
}

\section{Higher Education Pedagogy}

\section{Samina Malik ${ }^{1}$}

The increasing number of students enrolling into Higher Education and the work of teaching well demands reflective and flexible pedagogies which are not entirely predetermined. The higher education, today is both challenged and challenging. Two of the reasons for this are the changing focal points of learning as well as the instructors for whom the students are better knowledgeable in many fields due to knowledge explosion and wide range of information available on the internet. Today's learners have the abilities to locate, share and spread current information among their peer group. In this context, effective pedagogy prepares a better skilled and more knowledgeable workforce.

Teachers in Higher Education in Pakistan normally join the teaching profession with no formal necessary training or degree in pedagogy. In most cases, they develop pedagogical skills and competencies with experience or through social learning. But this form of learning pedagogy is both insufficient and inadequate, as transforming occupation to profession requires lot of deliberate efforts. It requires the highest integrity and competence for this transformation. Teachers should not assume that they have ample knowledge about their subject and that they can deliver it to all the diverse learners effectively. To teach effectively, the higher education faculty must be ready to update their knowledge in a wide range of topics along with hands on practice and professional development. It requires identification of the required skills according to the teachers' changing roles in a knowledge centered society; and supporting them by providing the conditions as they respond to the challenges of the knowledge society. Keeping this mind, we need to take cognizance of the fact that there is a dire need for more inductions into the teaching profession at the higher education level, across all subjects and levels. All teachers need to improve, not because they are not good enough, but because they can be even better.

Pertinent pedagogical training equips teachers with skills and expertise to facilitate learning in ways which enable them to go beyond using teacher centered approaches which focus on only transmitting knowledge from teachers

\footnotetext{
${ }^{1}$ Professor of Education/ Dean FSS, International Islamic University Islamabad Email: samina.malik@iiu.edu.pk/editor.ijitl@iiu.edu.pk
} 
to passive recipients. This training enables teachers to understand the role of assessment in teaching and learning, and to apply context-appropriate assessment techniques. The urgent need is to fulfill the long-term needs of the teaching profession in the higher education sector and to enhance the professional experience of higher education pedagogues planning professional development programs. For this, short courses as well as research and publication pertaining to teaching practices and learning skills as well as the development and implementation of professional standards for teachers is required. 